\title{
Social influence in childhood obesity interventions: a systematic review
}

\author{
M. S. Jalali, ${ }^{1}$ Z. Sharafi-Avarzaman, ${ }^{2}$ H. Rahmandad $^{1}$ and A. S. Ammerman ${ }^{3}$
}

\author{
${ }^{1}$ Sloan School of Management, Massachusetts \\ Institute of Technology, Cambridge, MA, USA, \\ ${ }^{2}$ Faculty of Economics and Business \\ Administration, Goethe University Frankfurt, \\ Frankfurt, Germany, and ${ }^{3}$ Center for Health \\ Promotion \& Disease Prevention, Gillings \\ School of Public Health, University of North \\ Carolina at Chapel Hill, Chapel Hill, NC, USA \\ Received 23 December 2015; accepted 23 \\ March 2016 \\ Address for correspondence: MS Jalali, Sloan \\ School of Management, Massachusetts \\ Institute of Technology, Cambridge, MA, USA. \\ E-mail: jalali@mit.edu
}

\begin{abstract}
Summary
The objective of this study is to understand the pathways through which social influence at the family level moderates the impact of childhood obesity interventions. We conducted a systematic review of obesity interventions in which parents' behaviours are targeted to change children's obesity outcomes, because of the potential social and environmental influence of parents on the nutrition and physical activity behaviours of children. PubMed (1966-2013) and the Web of Science (1900-2013) were searched, and 32 studies satisfied our inclusion criteria. Results for existing mechanisms that moderate parents' influence on children's behaviour are discussed, and a causal pathway diagram is developed to map out social influence mechanisms that affect childhood obesity. We provide health professionals and researchers with recommendations for leveraging family-based social influence mechanisms to increase the efficacy of obesity intervention programmes.
\end{abstract}

Keywords: Childhood obesity, family-based intervention, social influence, weightrelated behaviours.

Abbreviations: MQRS, methodological quality rating scale.

\section{Introduction}

Despite substantial efforts and much research, childhood obesity continues to be a significant public health concern. Beyond the biological and genetic causes of obesity, a growing consensus among researchers (e.g. (1-5)) points to the significant role of social factors in weight-related behaviours. A variety of weight-related behaviours associated with eating patterns, sedentary lifestyle and physical activity (e.g. (6-9)) can be influenced by social norms, family environments and relationships (2). Such influences have been shown to impact individuals' body weight $(10,11)$. For instance, a study by Dowda et al. (12) suggests that youths between the age of 8 and 16 years who have at least one overweight parent are more likely to be overweight compared with youths who do not have an overweight parent. Christakis and Fowler (4) estimate that an obese sibling or spouse can increase the probability of becoming obese by $40 \%$ and $37 \%$, respectively. Reviewing studies on the role of social influence in the obesity epidemic, Hammond (2) concludes that social influence is an important area of continued research and is promising for informing intervention design.

Although some obesity interventions leverage social influences to enhance their effectiveness, there is much room for designing interventions that better leverage social influence to impact weight-related behaviours. For example, Bahr et al. (10) argue that inefficacy of obesity interventions is partially because overweight and obese individuals are usually considered in isolation from their surrounding social context. However, teasing out the effect of social influence from other influences on 
behaviour is complicated, as the majority of obesity interventions that leverage social influence also have a direct effect on weight-related behaviour.

In this study, we review parent-based social influence mechanisms in obesity interventions in the family setting. We specifically focus on the family setting because (i) family relationships represent psychologically close ties in a shared environment and have significant potential to influence obesity (13-15) and (ii) the family setting is ripe for observing social influence mechanisms in action and their potential impact on weight-related behaviours (16). In this context, we focus on social influence that captures how children's weight-related opinions, emotions and behaviours are influenced by parents. For instance, parents can significantly impact children's health behaviours through modelling of behaviours, rewarding desirable behaviours and providing concrete resources to support certain behaviours, among others $(17,18)$. Moreover, to avoid confounding the mechanisms of social influence with other influence pathways in obesity interventions, we focus on studies that leverage a specific kind of family social influence, targeting parents to help with children's weight-related outcomes rather than intervening directly with the children.

\section{Methods}

\section{Search strategy}

We conducted a systematic review to study the effects and potential mechanisms of parent-based influence in obesity interventions in the family setting. We reviewed only those studies involving an intervention directed at parents with outcomes addressing children's eating and physical activity behaviours. This design limits the review to studies that capture only social influence of parents without confounding the direct effect of the intervention on children's behaviour. We looked for relevant papers in public health and social science journals listed in PubMed and the Web of Science. Search terms included 'family or family-based, parents, parent-focused or parent-led or family members', 'weight, overweight or obesity', 'intervention, trial, treatment or prevention' and any variation of those key terms.

\section{Inclusion/exclusion criteria}

Peer-reviewed full-text papers written in English and published from the inception of PubMed (1966) and the Web of Science (1900) to the end of 2013 were included. The inclusion and exclusion criteria were fully specified in the review protocol before conducting the review. Papers had to include an obesity intervention (prevention or treatment) directly targeting parents to influence the weight outcomes of children (e.g. intervening with parents with the distal goal of influencing children's weight status). Papers were excluded if they did not report weight and/or weightrelated behaviour outcomes for children, were not randomized trials, were reviews or meta-analyses, did not target family interactions, and involved medications or medical procedures, individuals with eating disorders or individuals in institutional settings.

\section{Data extraction}

Two reviewers independently performed data extraction to provide a detailed understanding of the interventions and their impacts. Data extraction was performed in two phases. In Phase 1, data was extracted based on the participants, intervention, comparison, outcome and time framework (19). In addition to participants, intervention, comparison, outcome and time variables, study objectives, country of study, participants' age, family members directly/indirectly targeted and key findings were extracted from each paper. The researchers also coded for whether one or both parents were targeted, the targeted behaviour and the social influence mechanisms.

In Phase 2, data extraction was based on coding the full text of studies, following standards for qualitative research (20), to code social influence mechanisms. Different interventions leveraged diverse activities and behaviours, underlying the need for an organizing framework to categorize the different social influence pathways used in each study. We therefore coded interventions for three core social influence mechanisms (21,22): (i) a supportive social environment, (ii) modelling healthy eating and activity patterns and (iii) praise and encouragement for desirable behaviours. Any disagreement or concern in the extracted data was discussed by the reviewers until consensus was reached. A third senior reviewer oversaw the design and conducting the reviews.

\section{Causal pathway diagram}

We also developed a causal pathway diagram to map out social influence mechanisms that affect childhood obesity. The diagram builds on the social ecological model for understanding childhood obesity $(23,24)$ and highlights the intermediate processes that regulate the causal mechanisms between intervention and outcomes hypothesized in various studies. The causal pathway diagramming method is adopted from systems modelling toolbox (25-27) and has diverse applications, including literature reviews (e.g. (28)). These diagrams provide a graphical summary of the key mechanisms identified in the literature, facilitate teasing out the empirical support for alternative pathways, highlight the areas in need of further empirical research and set the stage for future quantitative statistical and systems modelling as well as meta-analyses. 


\section{Quality assessment}

Quality assessment was carried out by two reviewers independently, using the methodological quality rating scale (MQRS). The MQRS was originally developed by Miller et al. (29), and we used the version adapted for family-based obesity interventions by Sung-Chan et al. (30). The quality attributes in the MQRS cover a wide range of quality aspects in key stages of interventions, such as design, implementation and maintenance. The measure contains 10 attributes, including study design (randomization and control group), treatment integrity (standardization, procedures and fidelity check), measures (reliability and validity), treatment intensity (duration), length of follow-up, attrition rate, statistical analyses, sample size, multisite and generalizability. Study design, treatment integrity, treatment intensity and length of follow-up have the highest score of $2(0,1$ or 2$)$, while the other attributes are dichotomous ( 0 or 1$)$; for more information about the definition of each attribute and measure, see (30). Each paper is assessed based on the MQRS attributes and scored between 0 and a maximum of 14 .

\section{Outcome score}

We used treatment effect scoring (30) to evaluate the effectiveness of interventions on weight-related outcomes. Treatment effect scoring compares weight reduction or changes in weight-related behaviours of the treatment group(s) versus the control group at the end of the intervention and after the follow-up. This method provides one of the following scores for each study: 1 = changes were not significant at the end of the intervention; 2 = changes were partially/marginally better at the end of the intervention; $3=$ changes were significant at the end of the intervention but not at the follow-up, or no follow-up results reported; and $4=$ changes were significant at the end of the intervention and at the follow-up.

\section{Results}

\section{Search results and description of studies}

The flow diagram for literature search is illustrated in Fig. 1. Using our search strategy, we identified 1,455 papers from

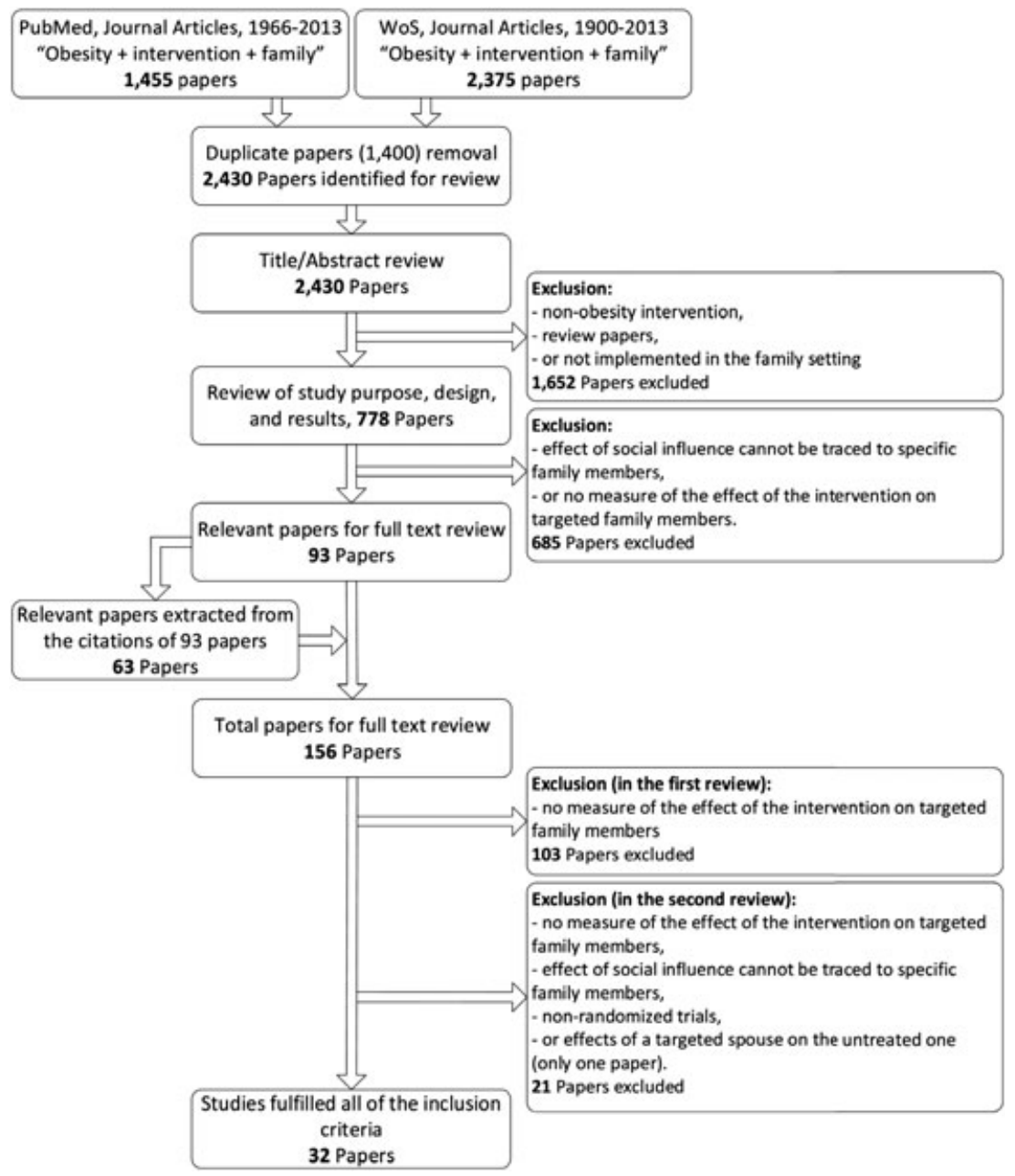

Figure 1 Flow diagram for literature search. 
PubMed and 2,375 papers from the Web of Science. After removing 1,400 duplicate papers, titles and abstracts of 2,430 papers were collected and screened. After excluding non-obesity interventions, review papers and studies not implemented within the family setting (1,652 papers), 778 papers remained. We then focused on study purpose, design and results; when compared with our inclusion criteria, 685 papers were subsequently excluded (e.g. studies in which the effect of social influence could not be traced to specific family members and studies that did not measure the effect of the intervention on targeted family members). Consequently, we reviewed the full text of 93 papers and also identified an additional 63 papers by tracking the citations of the first group, to be included in full text review.

Of 156 reviewed full-text papers, we excluded 124 papers because they did not provide any measure of the effect of intervention on children, or the effect of social influence could not be traced to specific family members. Table 1 presents examples of excluded papers in full-text review. Finally, 32 papers satisfied our inclusion criteria, which presented the effects of parent-led interventions on children (mean child age equal to 8 years). Both treatment interventions (23 papers) and prevention (9 papers) are included.

Twenty-eight studies targeted both parents, four focused on mothers and no studies focused on fathers alone. Eleven studies are implemented in the USA, 10 in Australia, four in Israel, two in the UK, four in Belgium, Germany, Switzerland and the Netherlands and one in the USA and Canada. Summaries of the interventions are included in Table 2 and the Online Supplementary Table S1. The analysis focuses on teasing out components of interventions, mechanisms of impact and outcomes to inform social influence processes and future intervention designs. The Online Supplementary Table S1 provides a detailed review of the studies, including study objective, intervention type and duration, participants, study design, findings and quantitative outcomes.

During the search process, we also looked for interventions that directly targeted any family member to influence the weight outcomes of another family member. We found only one paper (31) that presented the effects of targeting a spouse on the untreated spouse's behaviour. We did not include this study in our review to avoid increasing the heterogeneity of our sample.

\section{Behaviour change techniques}

Within each core social influence mechanism, we identified specific behaviour change techniques distilled from Abraham and Michie's taxonomy (85). For additional external validity, we mapped these techniques onto Kelman's variants of social influence $(21,86)$ (Table 3$)$. Seven behaviour change techniques summarized in Table 3 were utilized to varying degrees in the studies we reviewed - Table 3 presents the descriptions of these techniques and their associations with the core social influence mechanisms. For each intervention, the behaviour change techniques used are identified (see 'behaviour change' column in Table 2 and Fig. 2).

Among the techniques that targeted supportive social environments, the behaviour change techniques of plan social support or social change and prompt intention formation were the most prevalent, being observed in 69\% (22 papers) and $75 \%$ (24 papers) of the interventions, respectively (Fig. 2). Two other techniques were not widely utilized: provide instruction and guidance (16\%, five papers) and provide feedback on performance (6\%, two papers). It should also be noted that a supportive social environment needs proper and effective parenting style (see (87-89) for more discussion), while only $50 \%$ of the interventions (16 papers) focused specifically on parenting style (see parenting style in 'target behaviour' column in Table 2).

Among the rest of the behaviour change techniques, the potential technique of prompt identification as a role model was observed frequently $(78 \%, 25$ papers). Lastly, provide contingent rewards and provide general encouragement were observed in $47 \%$ (15 papers) and $25 \%$ ( 8 papers) of the interventions, respectively - see Fig. 2.

\section{Causal pathway diagram}

After reviewing selected papers and extracting the data, we summarized the results using a causal pathway diagram of the social influence mechanisms. Figure 3 captures the distinct causal mechanisms identified in the reviewed papers as potentially moderating the impact of parental interventions on childhood obesity. In other words, insights gained from the reviewed studies are

Table 1 Examples of excluded studies in the full text review

\begin{tabular}{ll}
\hline Study & Reasons for exclusion \\
\hline Kingsley and Shapiro (32), Israel, et al. (33), Israel, et al. (34), Israel, et al. (35), & Children are directly involved in the intervention. \\
McGarvey, et al. (36), Klohe-Lehman, et al. (37) & \\
Brownell, et al. (38), Klesges, et al. (39), Epstein, et al. (40), Epstein, et al. (41), & Not an intervention (i.e. study protocol, analysis only based \\
Epstein (42), De Bourdeaudhuij, et al. (43), Klesges, et al. (44), De Bock, et al. (45) & on a questionnaire, etc.) \\
Fisher, et al. (46), Arredondo, et al. (47), Campbell, et al. (48), Jones, et al. (49), & \\
Sanders (50), De Bock, et al. (51) &
\end{tabular}




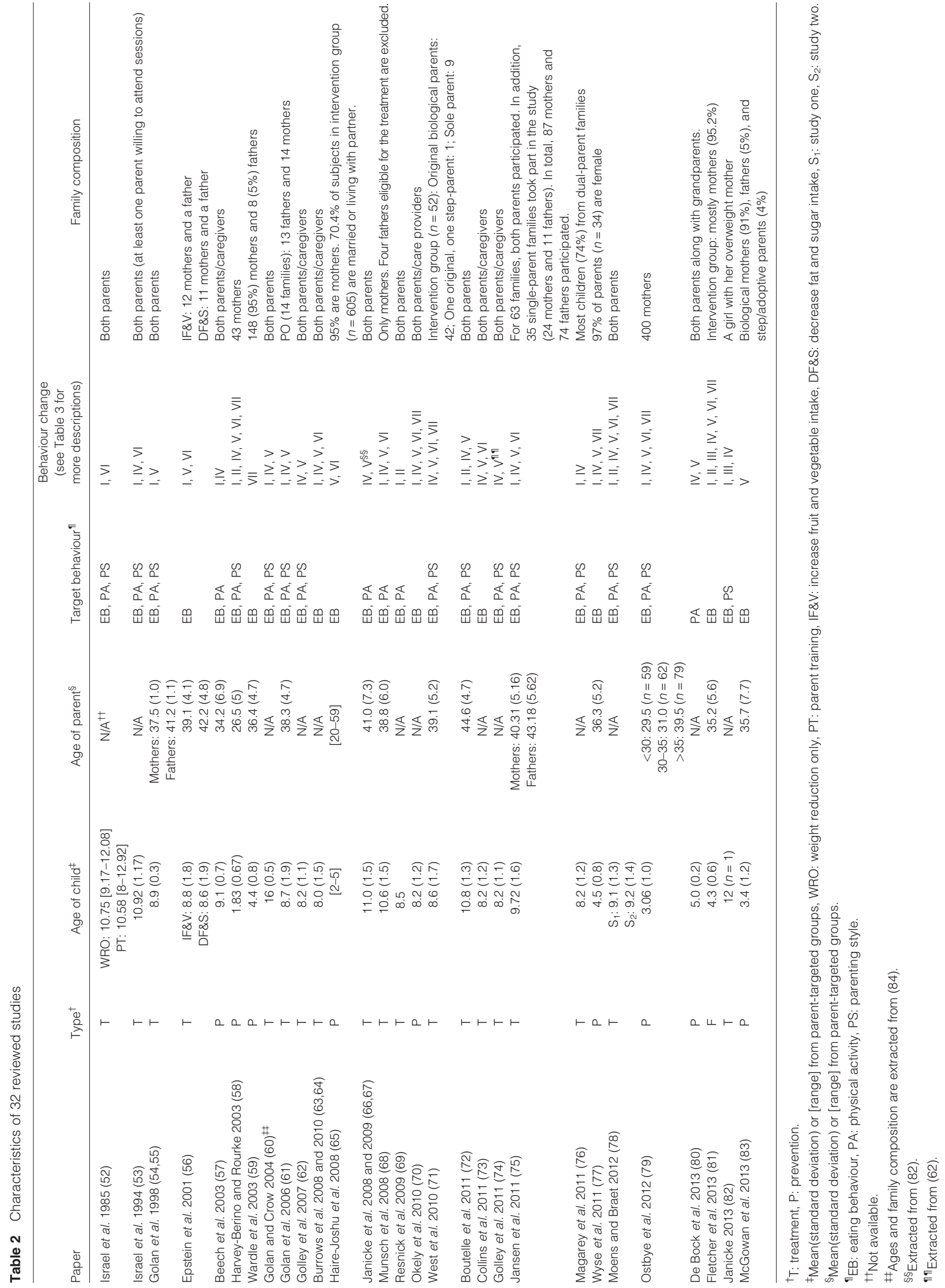


Table 3 Behaviour change through social influence

\begin{tabular}{|c|c|c|c|}
\hline $\begin{array}{l}\text { Core Social Influence } \\
\text { Mechanisms }\end{array}$ & $\begin{array}{l}\text { Behaviour change } \\
\text { techniques }^{\dagger}\end{array}$ & Descriptions (85) & $\begin{array}{l}\text { Kalman's varieties of social } \\
\text { influence }(21,86)\end{array}$ \\
\hline \multirow[t]{4}{*}{ Supportive social environment } & $\begin{array}{l}\text { Plan social support or } \\
\text { social change }(I)\end{array}$ & $\begin{array}{l}\text { 'Prompting consideration of how others could change their } \\
\text { behavior to offer the person help or (instrumental) social } \\
\text { support, including "buddy" systems and/or providing } \\
\text { social support.' }\end{array}$ & Internalization compliance \\
\hline & $\begin{array}{l}\text { Provide instruction and } \\
\text { guidance (II) }\end{array}$ & $\begin{array}{l}\text { 'Telling the person how to perform a behaviour and/or } \\
\text { preparatory behaviours.' }\end{array}$ & - \\
\hline & $\begin{array}{l}\text { Provide feedback on } \\
\text { performance (III) }\end{array}$ & $\begin{array}{l}\text { 'Providing data about recorded behaviour or evaluating } \\
\text { performance in relation to a set standard or others' } \\
\text { performance, i.e., the person received feedback on their } \\
\text { behaviour.' }\end{array}$ & - \\
\hline & $\begin{array}{l}\text { Prompt intention } \\
\text { formation (IV) }\end{array}$ & $\begin{array}{l}\text { 'Encouraging the person to decide to act or set a general } \\
\text { goal, for example, to make a behavioural resolution such } \\
\text { as "I will get more exercise next week".' }\end{array}$ & Internalization \\
\hline $\begin{array}{l}\text { Model healthy eating and } \\
\text { activity patterns }\end{array}$ & $\begin{array}{l}\text { Prompt identification as } \\
\text { a role model }(\mathrm{V})\end{array}$ & $\begin{array}{l}\text { 'Indicating how the person may be an example to others } \\
\text { and influence their behaviour or provide an opportunity for } \\
\text { the person to set a good example.' }\end{array}$ & Identification \\
\hline \multirow[t]{2}{*}{$\begin{array}{l}\text { Praise and encouragement } \\
\text { for desirable behaviours }\end{array}$} & $\begin{array}{l}\text { Provide contingent } \\
\text { rewards }(\mathrm{VI})\end{array}$ & $\begin{array}{l}\text { 'Praise, encouragement, or material rewards that are } \\
\text { explicitly linked to the achievement of specified behaviours.' }\end{array}$ & Compliance \\
\hline & $\begin{array}{l}\text { Provide general } \\
\text { encouragement (VII) }\end{array}$ & $\begin{array}{l}\text { 'Praising or rewarding the person for effort or performance } \\
\text { without this being contingent on specified behaviours or } \\
\text { standards of performance.' }\end{array}$ & Compliance \\
\hline
\end{tabular}

†The numbers associated with behavior change techniques are used in Table 2.

Behavior Change Techniques

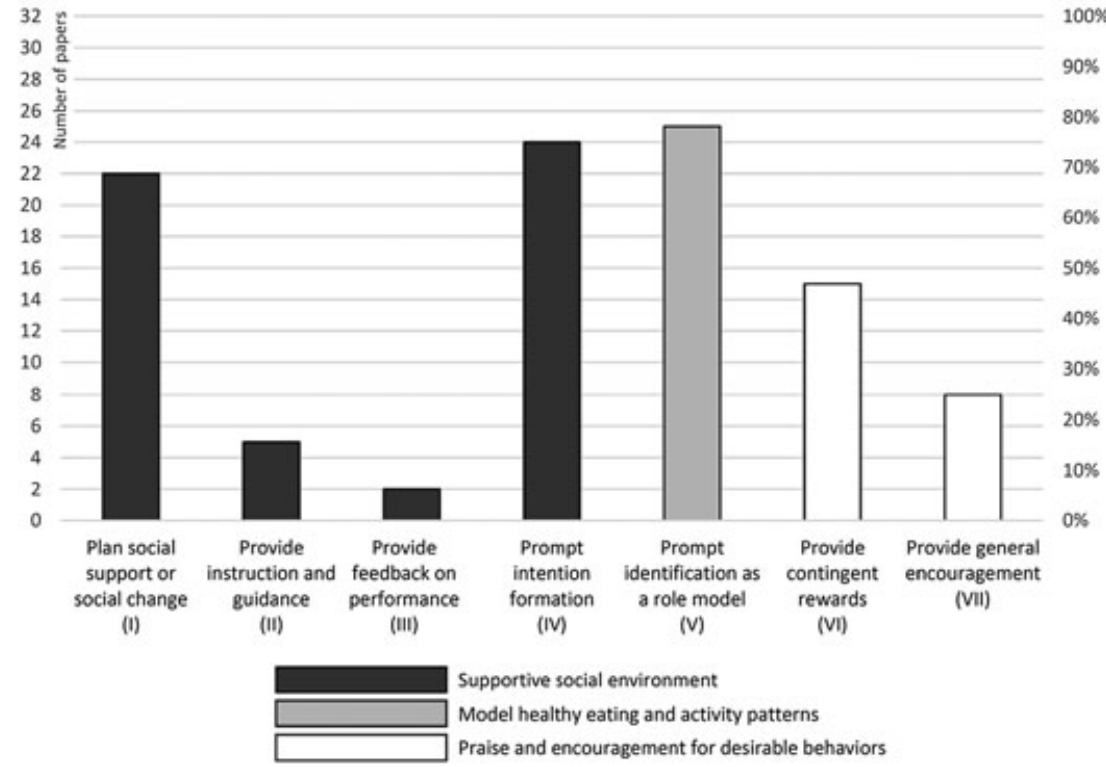

Figure 2 Behaviour change techniques used in the reviewed papers.

summarized as hypothesized causal mechanisms that connect different interventions to outcomes of interest, improving eating and activity behaviours. Given the level of detail in the Online Supplementary Table S1, Fig. 3 also helps illustrate the findings.

We relied on both explicit reports of mechanisms in the original studies (solid lines in Fig. 3) and our judgement about likely additional or implicit pathways (dashed lines). Figure 3 is divided into five layers that span the conceptual steps involved in these mechanisms: (i) components of intervention programmes; (ii) targeted parental behaviours; (iii) intermediate mechanisms (actions that transfer the effects of intervention programmes from the parents to the indirectly targeted 


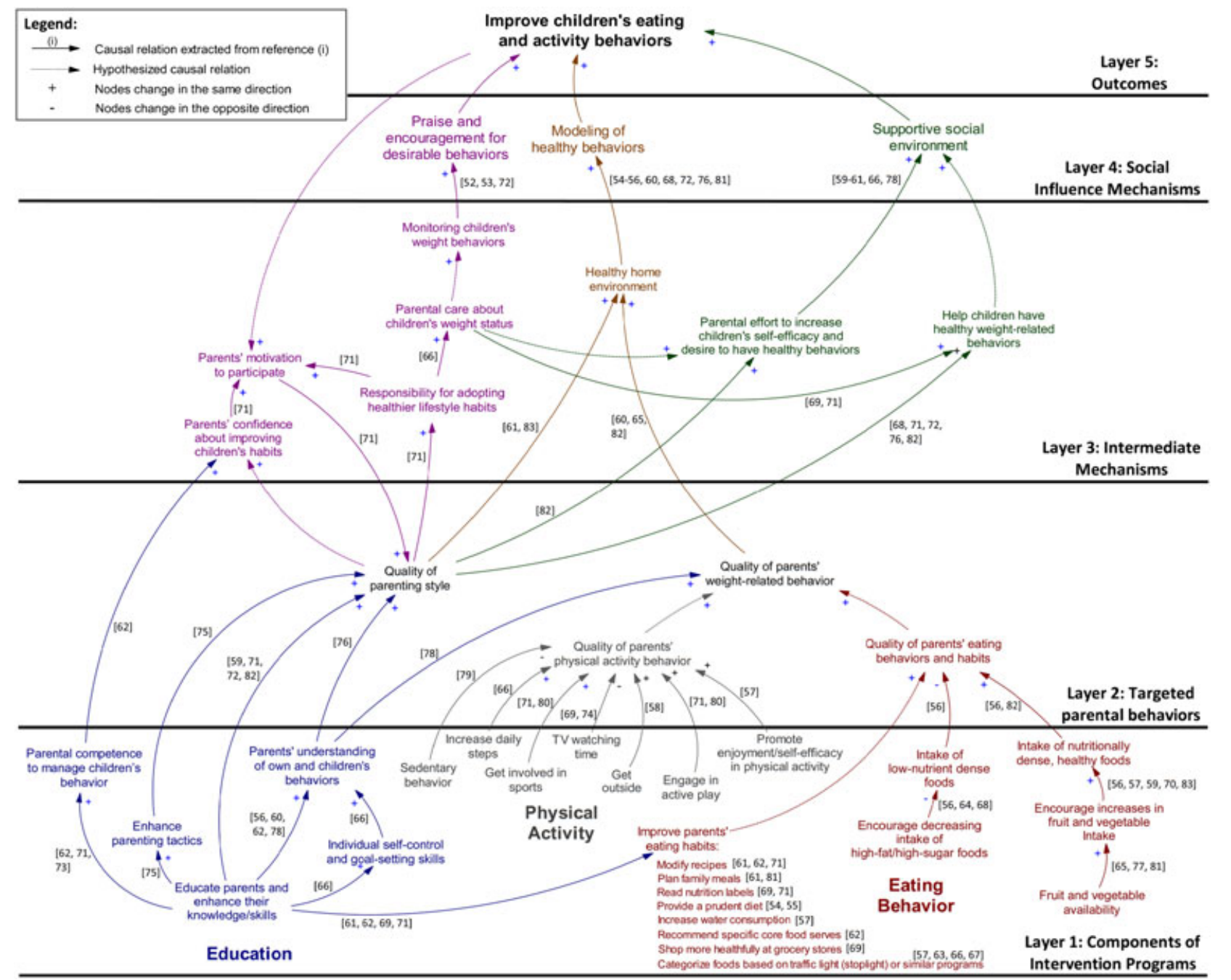

Figure 3 Causal pathway diagram.

family members, i.e., children); (iv) social influence mechanisms, which include the psychological consequences of the intermediate mechanisms; and (v) outcomes (e.g. improvements in child's eating and activity behaviours). Later, we discuss these five layers in more detail, noting that the causal pathways span these layers and are thus easier to follow along with the Fig. 3 diagram.

\section{Layer 1: Components of intervention programmes}

Three distinct components, education, physical activity and eating behaviour, can be identified as part of the interventions we reviewed (the bottom layer in Fig. 3). Some interventions focus more on one component than others, yet they all include these three elements to some extent. These components each activate several additional mechanisms relevant to understanding how social interventions work.
We first summarize the intervention components and then discuss the pathways through which they impact children's obesity outcomes.

\section{Parental education}

Parental education is a significant element in many of the interventions, although it is often accompanied by other components (90). Parental education aims to improve parents' own weight-related behaviour as well as their feeding style. Changes in parental responsibility for child feeding (91), encouraging nutritional variety and balance and modelling (92) have been reported.

In the reviewed interventions, some educational components enhance parents' understanding of their own and children's behaviours $(56,60,62,78)$ and parenting tactics (e.g. teaching parents to ignore undesirable behaviours and reward desirable behaviours) (75) and improve parents' competence in managing children's behaviour $(62,71,73)$. 
Moreover, some interventions include components related to individual self-control and goal setting to enhance parenting skills, e.g., (66).

\section{Physical activity and eating behaviour}

Many interventions also aimed to change parents' weightrelated behaviours. Interventions with physical activity components attempted to reduce sedentary behaviour (79), increase daily steps (66), get parents involved in sports $(71,80)$, reduce TV watching time $(69,74)$, encourage parents to get outside (58), engage parents in active play $(71,80)$ and promote enjoyment and self-efficacy in physical activity (57).

Interventions with eating behaviour components targeted improving parents' eating habits through modifying recipes $(61,62,71)$, planning family meals $(61,81)$, reading nutrition labels $(69,71)$, providing a prudent diet $(54,55)$, increasing water consumption (57), recommending core food servings (62), shopping for more healthful foods at grocery stores (69), categorizing foods based on traffic light (stoplight) or similar programmes $(57,63,66,67)$, encouraging decreased intake of high-fat and high-sugar foods $(56,64,68)$, increasing fruit and vegetable availability at home $(65,77,81)$ and increasing intake of nutritionally dense healthy foods $(56,57,59,70,83)$.

\section{Layers 2 and 3: Targeted parental behaviours and intermediate mechanisms}

The capabilities, routines and knowledge resulting from the previous components enhance a set of parental behaviours in their relationships with children $(71,76)$, which together we call quality of parenting style. These include taking responsibility for adopting healthier lifestyle habits at home (71), caring about a healthy home environment $(61,83)$, parental effort to instill a desire for healthy behaviour in children (82) and support for children's attempts to adopt healthy behaviours $(68,71,72,76,82)$.

By taking responsibility for adoption of healthy lifestyle habits, parents may become more motivated to participate in intervention components (71). That responsibility also enhances parents' caring about children's weight status (66), leading to better monitoring and feedback to change children's behaviour, one of the social influence mechanisms relevant to children's outcomes. Moreover, increased quality of parenting may lead to children's enhanced self-efficacy and increased desire to have healthy behaviours (82) and ultimately result in creating a supportive social environment at home (59-61,66,78).

Parental education can increase parents' competence to manage children's behaviour, improving parents' confidence in helping children change their habits (62) and enhancing parents' own motivation to continue participation in the intervention (71). Motivated parents also show a higher quality of parenting style (71). In fact, there is a potential virtuous cycle (reinforcing feedback loop) in which parents gain confidence, become more committed to the intervention and therefore perform better in their parenting style, paving the way for further successes and confidence-building.

Changing parents' own weight-related behaviours moderates the home environment, access and children's modelling of behaviours. Different studies have targeted different subsets of parents' activities, from reducing TV watching hours to increasing fruit and vegetable availability. Parental education also reinforces parental weight-related behaviour change as parents learn more about the importance of their own and children's behaviours (78). Once actively pursued, these healthy eating and activity behaviours of parents, together with improved parenting style, lead to healthier home environments $(60,61,65,82,83)$. Home environment, as a psychosocial antecedent for children's obesity (93), has the potential to change children's attitude towards different foods and activity levels $(55,94)$. Through modelling effects as well as access, healthy home environments could also regulate children's 'obesogenic' behaviours, such as regularity of participation in family meals, television viewing habits and healthy food consumption (61).

\section{Layer 4: Social influence mechanisms}

In the preceding section, we identified three core social influence mechanisms that moderate how parental interventions influence children's behaviours. We discuss these mechanisms in the succeeding text.

\section{Praising and encouraging desirable behaviours}

As parental attention increases the monitoring of children's weight-related behaviours, parents can provide praise and encouragement for desirable behaviours (and potentially punish undesirable ones). This type of social influence, also referred to as compliance (21) (Table 3), is not typically associated with enduring changes; in the absence of other influences, compliance often requires continued rewards and punishments to sustain the target behaviour (95). Ultimately, children must develop the ability to follow healthy eating and physical activity behaviours without much external feedback.

\section{Modelling of healthy eating and activity patterns}

Modelling is one of the main mechanisms by which behaviours transfer through social relations and has been strongly recommended for obesity interventions $(96,97)$. Social modelling occurs because people, often unconsciously, adjust their behaviours to match their valued social ties. This type of social influence (modelling) is also called identification $(21,95)$ (Table 3 ) and provides a pathway to more sustained change in children's behaviour. The key to 
activating this pathway is parental behaviour change, which provides a healthy home environment and opportunities for children to imitate parents' healthy behaviours (98). Given the reduction in the amount of time children spend with their parents and the adoption of role models outside of home as children age, identification is likely strongest for younger children (95), leading to the recommendation of using social influence for younger children (95). However, long-term follow-up studies are needed to track whether the modelled behaviours among younger children last into adulthood and whether this mechanism includes an age effect separate from the amount of time children spend with parents.

\section{Supportive social environment}

Providing a social environment supportive of healthy behaviours provides a third pathway to social influence. This mechanism is partially encouraged by a healthy home environment. Moreover, in a supportive environment, parents help children form their values and beliefs so that they actively choose healthy behaviours. This mechanism allows for the internalization (Table 3 ) of the target behaviours and is hypothesized to be the longest-lasting type of social influence and the one best suited for older children (95).

In our sample, parent interventions most frequently targeted building supportive social environments and modelling healthy eating and activity patterns (see items I, IV and $\mathrm{V}$ in Fig. 2 and Table 2) to promote healthy child weight.

\section{Layer 5: Outcomes}

Our main outcomes of interest are children's eating and physical activity behaviours, which directly influence obesity outcomes. The reviewed studies showed various levels of impact on children's obesity outcomes and weight-related behaviours. Because of small sample size and high heterogeneity among the studies (i.e. use of completely different mechanisms of impact and various reported weight-related outcomes), additional synthesis in the form of a quantitative aggregation of results using meta-regression or metaanalysis was ruled out.

\section{Quality assessment and outcome score}

The rating of 32 papers by two reviewers led to an overall initial disagreement of $27 \%$. The reviewers reached consensus and all initial disagreement were resolved. The MQRS scores ranged from 6 to 12 with a mean of 9.1 and median of 9 . We considered high methodological quality for studies with a score of more than $70 \%$ (MQRS score of 10 and above). Thirteen studies $(41 \%)$ received a score of 10 or above, while the 19 remaining studies received an average score of 7.9 - see Fig. 4a.

Figure $4 \mathrm{~b}$ also presents the treatment effect scores for the reviewed studies. The outcome scores ranged from 2 to 4 .
Nineteen papers $(59 \%)$ reported that significant changes were maintained at the last follow-up (score $=4), 8$ papers $(25 \%)$ reported significant changes (score $=3)$ at the end of the intervention, and 5 papers $(16 \%)$ reported marginally better changes (score $=2$ ) at the end of the intervention. Detailed quantitative outcomes for each paper are reported in the Online Supplementary Table S1.

\section{Discussion}

The choice of direct and indirect change agents within the family has recently received some attention in obesity research, e.g., see (30,93,99-102). A few family-based interventions target parents aiming to induce behavioural change in children. We provided a simple graphical summary (Fig. 3) of the key social influence mechanisms identified in the 32 reviewed papers, in which children are targeted indirectly. We also mapped out three core social mechanisms to seven behaviour change techniques and their use in the interventions (Tables 2 and 3). Analysing these mechanisms, we identified the provision of a supportive social environment for children as potentially the most beneficial social influence mechanism for older children and the modelling of healthy behaviour as especially useful for younger children (95). The choice of existing intervention designs, however, is not explicitly connected to these recommendations and may be better explained by feasibility constraints and other goals the studies have pursued. Therefore, significant diversity can be observed in the current designs and outcomes. The limited number of studies and heterogeneity in the designs and reported outcomes did not allow for insights from quantitative assessment of specific pathways. The reports on these interventions also did not provide enough detail to enable comparative cost-benefit analysis, an important need for designing cost-effective interventions.

In addition to the social influence mechanisms and the causal relations discussed in the analysis section, findings from the included studies provide insights on how to improve the efficacy of interventions. Specific recommendations adopted from the reviewed studies include: targeting families with young children (children younger than 11 years) $(61,66,76)$; starting treatment from early stages of obesity $(65,78)$, as more intensive interventions are usually required for obese children, focusing on what can be eaten versus what cannot be eaten (56) and focusing on health-centred rather than weight-centred approaches $(56,60)$. These recommendations are in line with focusing on providing a supportive social environment that leads to internalization of healthy behaviours in the family, rather than more narrowly defined obesity treatment goals.

Moreover, additional benefits are observed in treating parents as the direct agents of change in the family setting rather than treating the children directly (for more discussions of the roles of mothers and fathers, see 


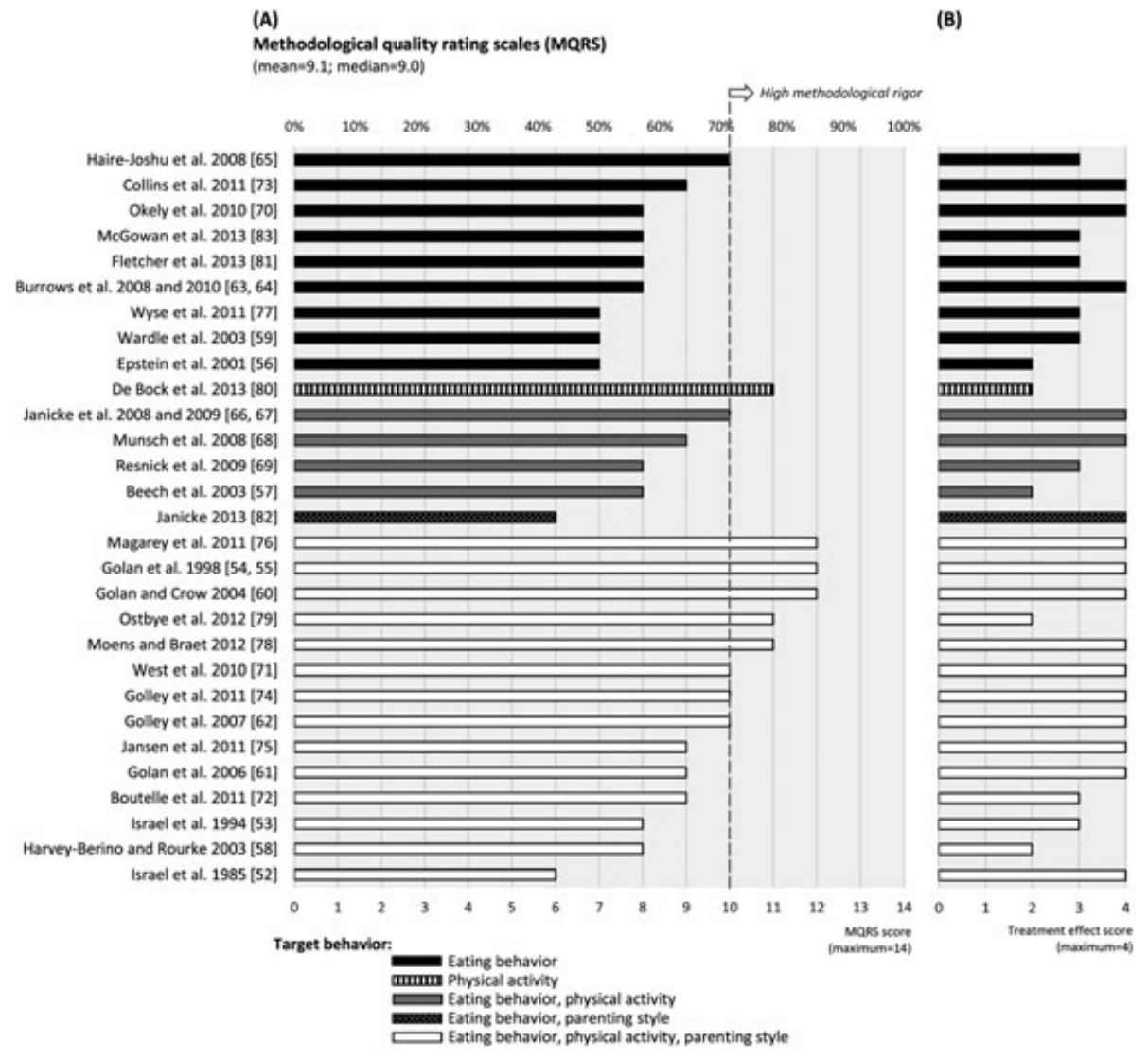

Figure 4 Methodological quality rating scale (MQRS) scores (a) and treatment effect scores (b).

$(103,104)$, and (105), respectively). These benefits relate more to the logistics and sustainability of interventions than to social influence mechanisms. First, focusing on parents reduces children's perception of having a health problem and the stigmatization that goes with being 'an obese patient' (60). As a result, children are less likely to resist the lifestyle changes that accompany the intervention (66). Moreover, parents usually have an easier time attending intervention sessions without children $(59,66)$, and the sessions are more productive in terms of problem solving and discussion time among participating parents (66). In addition, including fewer change agents reduces the costs of the interventions $(69,71,72)$ and makes the interventions more feasible for some, especially among underserved rural communities (61). The logistical benefits also enhance parents' motivation to participate, increasing the sustainability of the interventions and parents' commitment. Nevertheless, the current literature provides limited cost data to enable a systematic comparison of cost and benefits against alternative interventions.

There is considerable interest among obesity researchers in understanding the influence of systems on nutrition and physical activity behaviours. This goes more 'upstream' from the family and addresses the outer levels of the socio- ecological model, including community and organizational (e.g. school, faith-based organizations and community recreation programmes) factors as well as policy and environmental change at the local, state and national levels $(24,106)$. However, one can also consider systems change within the family, where parental training/education could lead to structuring the home environment so that the "healthy choice is the easy choice.' Here, the influence on children's behaviours is likely a combination of reinforcement, modelling and internalization, as well as a more direct impact of having access to healthy food and equipment/space promoting physical activity, and not having access to tempting foods and devices that promote sedentary behaviours (TV, computer games, etc.). One can even make the argument that families can have organizational 'policies' that create health-promoting environments. Children benefit from both directly experiencing this environment and learning how to structure one for themselves when they are able to make their own decisions.

During the search process, we did not limit our review to studies in which only children are targeted indirectly, but we considered any combination of family members. Interestingly, we found only one paper that presents the effects of a targeted spouse on the untreated partner, and we did not find any other combinations (within our inclusion criteria). This shows a potential research need for exploring 
the targeting of other combinations of family members, e.g., between spouses, among siblings, extended family members (e.g. grandparents) or even targeting children to change parents' outcomes.

Our review may be limited by selecting only peerreviewed studies published in English and focusing on a narrowly defined category of interventions. Nevertheless, the current review suggests that interventions that mainly utilize social influence pathways are potentially promising and offer a template for their mechanisms of impact. Much remains to be understood about the relative impact of such interventions in comparison with alternatives and the best study designs.

\section{Conflict of interest statement}

No conflict of interest was declared.

\section{Acknowledgements}

We would like to express our sincere gratitude to Kirsten Davison, Nancy Butte, Joanna Buscemi and Allison Doub for their feedback and detailed suggestions. We thank Linden Maya Thayer for her assistance in developing the summary table of the reviewed papers (the Online Supplementary Table S1). Partial financial support for this research was provided through National Institutes of Health Office of Behavioral and Social Sciences Research and NHLBI, grant 1R21HL113680-01.

\section{Supporting information}

Additional Supporting Information may be found in the online version of this article, http://dx.doi.org/10.1111/obr.12420

Table S1: Summary of 32 reviewed studies.

\section{References}

1. Koehly LM, Loscalzo A. Adolescent obesity and social networks. Prev Chronic Dis 2009; 6: A99.

2. Hammond RA. Social influence and obesity. Curr Opin Endocrinol Diabetes Obes 2010; 17: 467-471.

3. Ali MM, Amialchuk A, Heiland FW. Weight-related behavior among adolescents: the role of peer effects. Plos One 2011; 6: e21179.

4. Christakis NA, Fowler JH. The spread of obesity in a large social network over 32 years. N Engl J Med 2007; 357: 370-379.

5. Burke MA, Heiland F. Social dynamics of obesity. Econ Inq 2007; 45: 571-591.

6. Salvy SJ et al.. Influence of peers and friends on children's and adolescents' eating and activity behaviors. Physiol Behav 2012; 106: 369-378.

7. Pachucki MA, Jacques PF, Christakis NA. Social network concordance in food choice among spouses, friends, and siblings. Am J Public Health 2011; 101: 2170-2177.
8. Liao Y et al.. Which type of sedentary behaviour intervention is more effective at reducing body mass index in children? A metaanalytic review. Obes Rev 2014; 15: 159-168.

9. Prince SA et al.. A comparison of the effectiveness of physical activity and sedentary behaviour interventions in reducing sedentary time in adults: a systematic review and meta-analysis of controlled trials. Obes Rev 2014; 15: 905-19.

10. Bahr DB et al.. Exploiting social networks to mitigate the obesity epidemic. Obesity 2009; 17: 723-728.

11. Hammond RA, Ornstein JT. A model of social influence on body mass index. Ann N Y Acad Sci 2014; 1331: 34-42.

12. Dowda $\mathrm{M}$ et al.. Environmental influences, physical activity, and weight status in 8- to 16-year-olds. Arch Pediatr Adolesc Med 2001; 155: 711-717.

13. Leahey TM et al.. Social influences are associated with BMI and weight loss intentions in young adults. Obesity 2011; 19 : 1157-1162.

14. Marsh $\mathrm{S}$ et al.. Family-based interventions for reducing sedentary time in youth: a systematic review of randomized controlled trials. Obes Rev 2014; 15: 117-133.

15. Anzman SL, Rollins BY, Birch LL. Parental influence on children's early eating environments and obesity risk: implications for prevention. Int J Obes (Lond) 2010; 34: 1116-24.

16. White JM, Klein DM. Family Theories, 3rd edn. Sage Publications: Los Angeles xiii, 2008, pp. 333.

17. Evans AE et al.. Changing the home nutrition environment effects of a nutrition and media literacy pilot intervention. Fam Community Health 2006; 29: 43-54.

18. Epstein LH. Family-based behavioural intervention for obese children. Int J Obes Relat Metab Disord: journal of the International Association for the Study of Obesity 1996; 20: S14-21.

19. Haynes RB. Clinical Epidemiology: How to do Clinical Practice Research, 3rd edn. Lippincott Williams \& Wilkins: Philadelphia xv, 2006, pp. 496.

20. Patton MQ, Patton MQ. Qualitative Research and Evaluation Methods, 3 edn. Sage Publications: Thousand Oaks, Calif. xxiv, 2002, pp. 59865 p.

21. Kelman HC. Compliance, identification, and internalization: three processes of attitude change. J Confl Resolut 1958; 2: 51-60. 22. Herman CP, Roth DA, Polivy J. Effects of the presence of others on food intake: a normative interpretation. Psychol Bull 2003; 129: 873-886.

23. McLeroy KR et al.. An ecological perspective on health promotion programs. Health Educ Q 1988; 15: 351-77.

24. Davison KK, Birch LL. Childhood overweight: a contextual model and recommendations for future research. Obes Rev 2001; 2: $159-71$

25. Sterman J. Business Dynamics: Systems Thinking and Modeling for a Complex World. Irwin/McGraw-Hill: Boston xxvi, 2000, pp. 982.

26. Jalali, MS, et al. Dynamics of Obesity Interventions inside Organizations. in The 32nd International Conference of the System Dynamics Society. 2014. System Dynamics Society.

27. Rahmandad, H, N Sabounchi, Building and Estimating a Dynamic Model of Weight Gain and Loss for Individuals and Populations. Proceedings from The 29th International Conference of the System Dynamics Society, 2011.

28. Hu K et al.. Factors influencing the risk of falls in the construction industry: a review of the evidence. Constr Manag Econ 2011; 29: 397-416.

29. Miller WR et al.. What works? A methodological analysis of the alcohol treatment outcome literature. In: Miller RKHWR (ed.). Handbook of Alcoholism Treatment Approaches: Effective 
Alternatives, 2nd edn. Allyn \& Bacon: Needham Heights, MA, US, 1995, pp. 12-44.

30. Sung-Chan P et al.. Family-based models for childhood-obesity intervention: a systematic review of randomized controlled trials. Obes Rev 2013; 14: 265-278.

31. Gorin AA et al.. Weight loss treatment influences untreated spouses and the home environment: evidence of a ripple effect. Int J Obes (Lond) 2008; 32: 1678-84.

32. Kingsley RG, Shapiro J. A comparison of three behavioral programs for the control of obesity in children. Behav Ther 1977; 8: 30-36.

33. Israel AC et al.. An evaluation of two methods of parental involvement in treating obese children. Behav Ther 1984; 15: 266-272.

34. Israel AC, Silverman WK, Solotar LC. An investigation of family influences on initial weight status, attrition, and treatment outcome in a childhood obesity program. Behav Ther 1986; 17: 131-143.

35. Israel AC, Solotar LC, Zimand E. An investigation of two parental involvement roles in the treatment of obese children. Int $J$ Eat Disord 1990; 9: 557-564.

36. McGarvey E et al.. Feasibility and benefits of a parent-focused preschool child obesity intervention. Am J Public Health 2004; 94: 1490-5.

37. Klohe-Lehman DM et al.. Low-income, overweight and obese mothers as agents of change to improve food choices, fat habits, and physical activity in their 1-to-3-year-old children. J Am Coll Nutr 2007; 26: 196-208.

38. Brownell KD, Kelman JH, Stunkard AJ. Treatment of obese children with and without their mothers: changes in weight and blood pressure. Pediatrics 1983; 71: 515-523.

39. Klesges RC et al.. Parental influences on children's eating behavior and relative weight. I Appl Behav Anal 1983; 16: 371-378. 40. Epstein LH et al.. Ten-year outcomes of behavioral family-based treatment for childhood obesity. Health Psychol 1994; 13: 373-83.

41. Epstein LH et al.. Effects of decreasing sedentary behavior and increasing activity on weight change in obese children. Health Psychol 1995; 14: 109-15.

42. Epstein LH. Family-based behavioural intervention for obese children. Int J Obes Relat Metab Disord 1996; 20: S14-21.

43. De Bourdeaudhuij I et al.. Differences in impact between a family- versus an individual-based tailored intervention to reduce fat intake. Health Educ Res 2002; 17: 435-49.

44. Klesges RC et al.. Memphis Girls health Enrichment Multi-site Studies (GEMS): Phase 2: design and baseline. Contemp Clin Trials 2008; 29: 42-55.

45. De Bock F, Breitenstein L, Fischer JE. Positive impact of a preschool-based nutritional intervention on children's fruit and vegetable intake: results of a cluster-randomized trial. Public Health Nutr 2012; 15: 466-475.

46. Fisher JO et al.. Parental influences on young girls' fruit and vegetable, micronutrient, and fat intakes. J Am Diet Assoc 2002: 58-64.

47. Arredondo EM et al.. Is parenting style related to children's healthy eating and physical activity in Latino families? Health Educ Res 2006; 21: 862-871.

48. Campbell KJ, Crawford DA, Ball K. Family food environment and dietary behaviors likely to promote fatness in 5-6 year-old children. Int J Obes (Lond) 2006; 30: 1272-1280.

49. Jones RA et al.. The HIKCUPS trial: a multi-site randomized controlled trial of a combined physical activity skill-development and dietary modification program in overweight and obese children. BMC Public Health 2007; 7: 15.

50. Sanders MR. Triple P - Positive Parenting Program as a public health approach to strengthening parenting. J Fam Psychol 2008; 22: 506-517.
51. De Bock F et al.. A participatory parent-focused intervention promoting physical activity in preschools: design of a clusterrandomized trial. BMC Public Health 2010; 10: 49.

52. Israel AC, Stolmaker L, Andrian CAG. The effects of training parents in general child management skills on a behavioral weight loss program for children. Behav Ther 1985; 16: 169-180.

53. Israel AC et al.. An evaluation of enhanced self-regulation training in the treatment of childhood obesity. J Pediatr Psychol 1994; 19: 737-49.

54. Golan M, Fainaru M, Weizman A. Role of behaviour modification in the treatment of childhood obesity with the parents as the exclusive agents of change. Int I Obes Relat Metab Disord 1998; 22: 1217-24.

55. Golan $\mathrm{M}$ et al.. Parents as the exclusive agents of change in the treatment of childhood obesity. Am J Clin Nutr 1998; 67: $1130-1135$.

56. Epstein LH et al.. Increasing fruit and vegetable intake and decreasing fat and sugar intake in families at risk for childhood obesity. Obes Res 2001; 9: 171-8.

57. Beech BM et al.. Child- and parent-targeted interventions: the Memphis GEMS pilot study. Ethn Dis 2003; 13: S40-53.

58. Harvey-Berino J, Rourke J. Obesity prevention in preschool native-American children: a pilot study using home visiting. Obes Res 2003; 11: 606-11.

59. Wardle J et al.. Increasing children's acceptance of vegetables; a randomized trial of parent-led exposure. Appetite 2003; 40: 155-162. 60. Golan M, Crow S. Targeting parents exclusively in the treatment of childhood obesity: long-term results. Obes Res 2004; 12 : 357-61.

61. Golan M, Kaufman V, Shahar DR. Childhood obesity treatment: targeting parents exclusively v. parents and children. $\mathrm{Br} J$ Nutr 2006; 95: 1008-15.

62. Golley RK et al.. Twelve-month effectiveness of a parent-led, family-focused weight-management program for prepubertal children: a randomized, controlled trial. Pediatrics 2007; 119: 517-25. 63. Burrows $\mathrm{T}$ et al.. Impact of a child obesity intervention on dietary intake and behaviors. Int J Obes (Lond) 2008; 32: 1481+. 64. Burrows T, Warren JM, Collins CE. The impact of a child obesity treatment intervention on parent-child-feeding practices. Int $\mathrm{J}$ Pediatr Obes 2010; 5: 43-50.

65. Haire-Joshu D et al. High 5 for kids: the impact of a home visiting program on fruit and vegetable intake of parents and their preschool children. Prev Med 2008; 47: 77-82.

66. Janicke DM et al.. Comparison of parent-only vs family-based interventions for overweight children in underserved rural settings: outcomes from project STORY. Arch Pediatr Adolesc Med 2008; 162: $1119-25$.

67. Janicke DM et al.. Comparison of program costs for parentonly and family-based interventions for pediatric obesity in medically underserved rural settings. J Rural Health 2009; 25: 326-330. 68. Munsch $S$ et al.. Randomized controlled comparison of two cognitive behavioral therapies for obese children: mother versus mother-child cognitive behavioral therapy. Psychother Psychosom 2008; 77: 235-46.

69. Resnick EA et al.. The CHEER study to reduce BMI in elementary school students: a school-based, parent-directed study in Framingham, Massachusetts. J Sch Nurs 2009; 25: 361-72.

70. Okely AD et al.. Multi-site randomized controlled trial of a child-centered physical activity program, a parent-centered dietary-modification program, or both in overweight children: the HIKCUPS study. J Pediatr 2010; 157: 388-394.

71. West $\mathrm{F}$ et al.. Randomised clinical trial of a family-based lifestyle intervention for childhood obesity involving parents as the exclusive agents of change. Behav Res Ther 2010; 48: 1170-9. 
72. Boutelle KN, Cafri G, Crow SJ. Parent-only treatment for childhood obesity: a randomized controlled trial. Obesity 2011; 19: $574-580$.

73. Collins CE et al.. Parent diet modification, child activity, or both in obese children: an RCT. Pediatrics 2011; 127: 619-27.

74. Golley RK, Magarey AM, Daniels LA. Children's food and activity patterns following a six-month child weight management program. Int J Pediatr Obes 2011; 6: 409-414.

75. Jansen E, Mulkens S, Jansen A. Tackling childhood overweight: treating parents exclusively is effective. Int J Obes (Lond) 2011; 35: 501-509.

76. Magarey AM et al.. A parent-led family-focused treatment program for overweight children aged 5 to 9 years: the PEACH RCT. Pediatrics 2011; 127: 214-222.

77. Wyse R et al.. A pilot study of a telephone-based parental intervention to increase fruit and vegetable consumption in 3-5-year-old children. Public Health Nutr 2011; 14: 2245-2253.

78. Moens E, Braet C. Training parents of overweight children in parenting skills: a 12-month evaluation. Behav Cogn Psychother 2012; 40: 1-18.

79. Ostbye $\mathrm{T}$ et al.. Parent-focused change to prevent obesity in preschoolers: results from the KAN-DO study. Prev Med 2012; 55: 188-95.

80. De Bock F et al.. A participatory physical activity intervention in preschools: a cluster randomized controlled trial. Am J Prev Med 2013; 45: 64-74.

81. Fletcher A et al.. A randomised controlled trial and mediation analysis of the 'Healthy Habits', telephone-based dietary intervention for preschool children. Int J Behav Nutr Phys Act 2013; 10: pp. 43. 82. Janicke DM. Treatment of pediatric obesity using a parent-only approach: a case example. Health Psychol 2013; 32: 345-350.

83. McGowan L et al.. Healthy feeding habits: efficacy results from a cluster-randomized, controlled exploratory trial of a novel, habitbased intervention with parents. Am J Clin Nutr 2013; 98: 769-777. 84. Golan $\mathrm{M}$ et al.. Parents as the exclusive agents of change in the treatment of childhood obesity. Am J Clin Nutr 1998; 67: 1130-5. 85. Abraham C, Michie S. A taxonomy of behavior change techniques used in interventions. Health Psychol 2008; 27: 379-87.

86. Kelman HC. Interests, relationships, identities: three central issues for individuals and groups in negotiating their social environment. Annu Rev Psychol 2006; 57: 1-26.

87. van der Kruk JJ et al.. Obesity: a systematic review on parental involvement in long-term European childhood weight control interventions with a nutritional focus. Obes Rev 2013; 14: 745-760.

88. Baranowski T et al.. Houston... We have a problem! Measurement of parenting. Child Obes 2013; 9: S1-4.

89. Hughes SO et al.. Revisiting a neglected construct: parenting styles in a child-feeding context. Appetite 2005; 44: 83-92.

90. Nichols JL. Changing public behavior for better health: is education enough? Am J Prev Med 1994; 10: 19-22.
91. Birch LL, Doub AE. Learning to eat: birth to age 2 y. Am J Clin Nutr 2014; 99: 723s-8s.

92. Musher-Eizenman D, Holub S. Comprehensive Feeding Practices Questionnaire: validation of a new measure of parental feeding practices. J Pediatr Psychol 2007; 32: 960-72.

93. Knowlden AP, Sharma M. Systematic review of family and home-based interventions targeting paediatric overweight and obesity. Obes Rev 2012; 13: 499-508.

94. Patrick H, Nicklas TA. A review of family and social determinants of children's eating patterns and diet quality. J Am Coll Nutr 2005; 24: 83-92.

95. Aronson, E, The Social Animal, Seventh Edition. The social animal, Seventh edition. 1995: W. H. Freeman and Co., 37th Floor, 41 Madison Ave., New York, New York 10010, USA; W. H. Freeman and Co. Ltd., 20 Beaumont Street, OX1 2NQ Oxford, England, UK. $\mathrm{xx}+515 \mathrm{p}$.

96. Gibson EL et al.. A narrative review of psychological and educational strategies applied to young children's eating behaviours aimed at reducing obesity risk. Obes Rev 2012; 13: 85-95.

97. Summerbell CD et al.. Evidence-based recommendations for the development of obesity prevention programs targeted at preschool children. Obes Rev 2012; 13: 129-132.

98. Chartrand TL, van Baaren R. Human mimicry. In: Zanna MP (ed.). Advances in Experimental Social Psychology, Vol. 41, 2009, pp. 219-274.

99. Jull A, Chen R. Parent-only vs. parent-child (family-focused) approaches for weight loss in obese and overweight children: a systematic review and meta-analysis. Obes Rev 2013; 14: 761-768.

100. Yavuz HM et al.. Interventions aimed at reducing obesity in early childhood: a meta-analysis of programs that involve parents. J Child Psychol Psychiatry 2015; 56: 677-92.

101. Golley RK et al.. Interventions that involve parents to improve children's weight-related nutrition intake and activity patterns - what nutrition and activity targets and behaviour change techniques are associated with intervention effectiveness? Obes Rev 2011; 12: 114-30.

102. Skouteris $\mathrm{H}$ et al.. Parental influence and obesity prevention in pre-schoolers: a systematic review of interventions. Obes Rev 2011; 12: 315-328.

103. Jackson D et al.. Overweight and obese children: mothers' strategies. J Adv Nurs 2005; 52: 6-13.

104. Spruijt-Metz D et al.. Relation between mothers' childfeeding practices and children's adiposity. Am J Clin Nutr 2002; 75: 581-586.

105. Khandpur $\mathrm{N}$ et al.. Fathers' child feeding practices: a review of the evidence. Appetite 2014; 78: 110-21.

106. Harrison $\mathrm{K}$ et al.. Toward a developmental conceptualization of contributors to overweight and obesity in childhood: the six-Cs model. Child Dev Perspect 2011; 5: 50-58. 